\title{
Annual and Interannual Variability of the Tropical Instability Vortices in the Equatorial Eastern Pacific Observed from Lagrangian Surface Drifters ${ }^{\mathfrak{a}}$
}

\author{
SHAOJUN ZHENG \\ State Key Laboratory of Tropical Oceanography, South China Sea Institute of Oceanology, \\ Chinese Academy of Sciences, Guangzhou, China, and CSIRO Oceans and Atmosphere, \\ Floreat, Western Australia, Australia \\ MING FENG \\ CSIRO Oceans and Atmosphere, Floreat, Western Australia, Australia \\ YAN Du AND XuHuA CHENG \\ State Key Laboratory of Tropical Oceanography, South China Sea Institute of Oceanology, \\ Chinese Academy of Sciences, Guangzhou, China \\ JIAXUN LI \\ Naval Institute of Hydrographic Surveying and Charting, Tianjin, China
}

(Manuscript received 9 February 2016, in final form 8 September 2016)

\begin{abstract}
This study documents the spatial distributions and temporal variations of anticyclonic eddies with identified radii $\geq 100 \mathrm{~km}$ in the equatorial eastern tropical Pacific Ocean [viz., tropical instability vortices (TIVs)] using Lagrangian surface drifters. The TIVs identified from Lagrangian surface drifters are distributed in a band along $5^{\circ} \mathrm{N}$ and are closely associated with latitudinal barotropically unstable shear between the westward South Equatorial Current (SEC) and the eastward North Equatorial Countercurrent (NECC). Fewer TIVs are identified from February to June when the shear between the SEC and NECC is weak, whereas more TIVs are found from July to January when the shear is enhanced. The number of identified TIVs also exhibits substantial interannual variability, with fewer TIVs identified during El Niño events and more TIVs found during La Niña events. This relationship is likely associated with the interannual variations of the zonal circulation in the equatorial Pacific modulated by El Niño-Southern Oscillation (ENSO).
\end{abstract}

\section{Introduction}

Mesoscale eddies are ubiquitous in global oceans and play an important role in ocean circulation through heat and mass transport (Zhang et al. 2014; Dong et al. 2014). In

Supplemental information related to this paper is available at the Journals Online website: http://dx.doi.org/10.1175/ JCLI-D-16-0124.s1.

Corresponding author address: Shaojun Zheng, State Key Laboratory of Tropical Oceanography, South China Sea Institute of Oceanology, Chinese Academy of Sciences, 164 West Xingang Road, Guangzhou 510301, China.

E-mail: zhengshaojun@scsio.ac.cn; duyan@scsio.ac.cn the equatorial eastern tropical Pacific Ocean (EETPO; $\left.0^{\circ}-10^{\circ} \mathrm{N}, 170^{\circ} \mathrm{E}-80^{\circ} \mathrm{W}\right)$, the typical anticyclonic eddies [viz., the tropical instability vortices (TIVs); Willett et al. 2006] exhibit energetic horizontal and vertical circulation (Holmes et al. 2014). The TIVs have a diameter of approximately $300-500 \mathrm{~km}$ between $3^{\circ}$ and $8^{\circ} \mathrm{N}$, exhibit westward-propagating phase speeds of $0.3 \mathrm{~m} \mathrm{~s}^{-1}$, and are closely associated with tropical instability waves (TIWs; Hansen and Maul 1991; Legeckis 1977; Kennan and Flament 2000), which have wavelengths of $1000-2000 \mathrm{~km}$ and westward phase speeds of approximately $0.5 \mathrm{~m} \mathrm{~s}^{-1}$ (Contreras 2002; Qiao and Weisberg 1995). The TIVs appear to form only north of the equator (Flament et al. 1996; Legeckis et al. 2004; Weidman et al. 1999). The TIVs 
(a) Surface circulation scheme

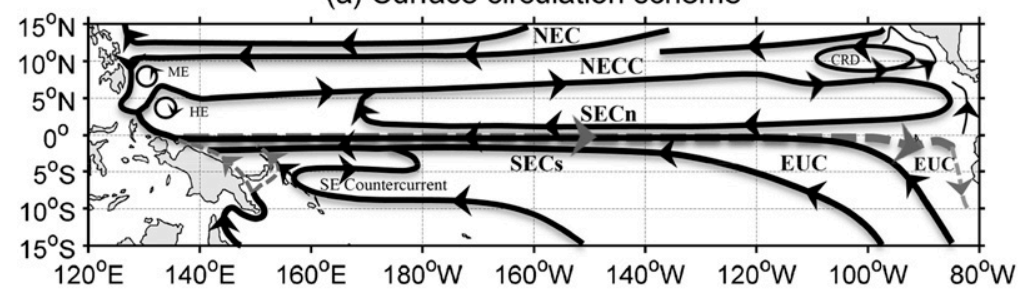

(b) Climatological current from surface drifters

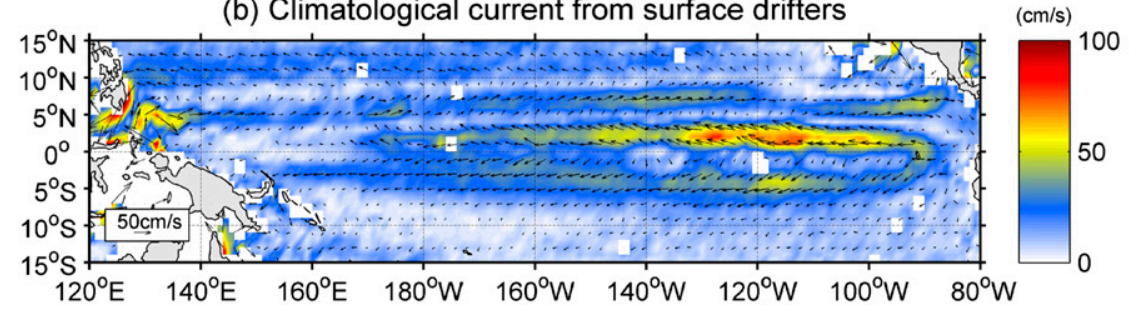

(c) Number of surface drifter observations

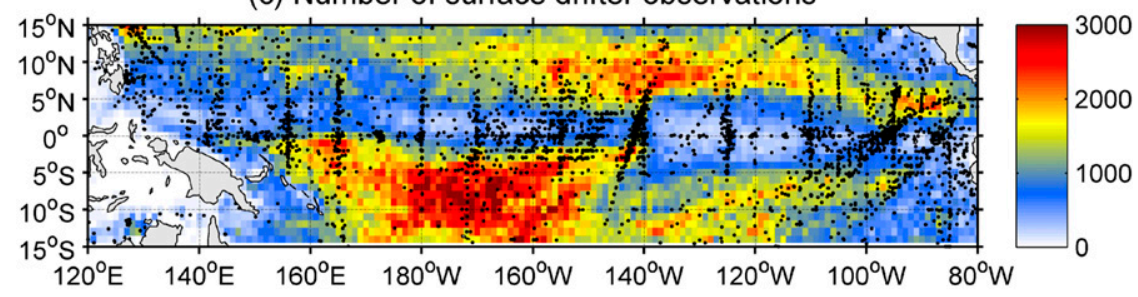

(d) EKE

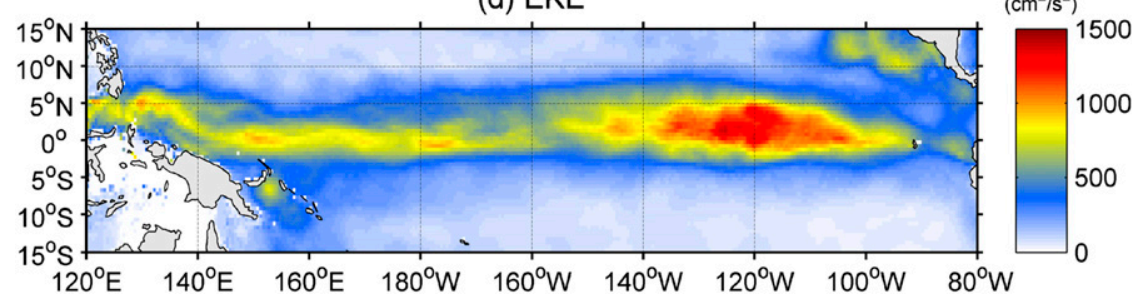

FIG. 1. (a) Surface circulation schematic in the TPO $\left(15^{\circ} \mathrm{S}-15^{\circ} \mathrm{N}, 120^{\circ} \mathrm{E}-80^{\circ} \mathrm{W}\right)$ modified from Talley et al. (2011). Major near-surface undercurrents at the equator and along the eastern boundary are also shown (dashed) [Costa Rica Dome (CRD)]. (b) Climatological currents (vectors) of the TPO from surface drifters (Lumpkin and Johnson 2013). The shaded color represents speed $\left(\mathrm{cm} \mathrm{s}^{-1}\right)$. (c) Number of surface drifter 6-h observations in each $1^{\circ} \times 1^{\circ}$ bin with released position (black dots). (d) EKE $\left(\mathrm{cm}^{2} \mathrm{~s}^{-2}\right.$ ) from surface drifters (Lumpkin and Johnson 2013).

and the TIWs are coherent in phase with the 30-35-day oscillations associated with unstable first-meridional-mode Rossby waves (Lyman et al. 2007; Ubelmann and Fu 2011). The TIVs are the manifestation of an energetic TIW field where individual TIWs have rolled up into nonlinear anticyclonic vortices with a recirculating velocity field. Thus, the TIVs and the TIWs should share similar energy sources. The TIWs result from latitudinal barotropically unstable shear between the westward South Equatorial Current (SEC) and the eastward North Equatorial Countercurrent (NECC; Fig. 1a), as suggested by numerical models (Cox 1980; Donohue and Wimbush 1998; Lyman et al. 2005; Philander 1978) and observational studies (Baturin and Niiler 1997; Kennan and Flament 2000; Luther and Johnson 1990), and have a potential additional source of energy from baroclinic instability (Cox 1980; Luther and Johnson 1990; Lyman et al. 2005; Masina et al. 1999).

The surface current climatology derived from Lagrangian surface drifters (Fig. 1b) captures ocean surface circulation patterns in the tropical Pacific Ocean (TPO; $15^{\circ} \mathrm{S}-15^{\circ} \mathrm{N}, 120^{\circ} \mathrm{E}-80^{\circ} \mathrm{W}$ ), especially the SEC and the NECC. Following the definition of Wyrtki (1974), the SEC is separated into south and north branches referred to as the SECs and the SECn, respectively. The SECn is stronger, with a maximum westward speed of approximately $1 \mathrm{~m} \mathrm{~s}^{-1}$ at $2.5^{\circ} \mathrm{N}$. The SECn builds its strength when it flows from $90^{\circ}$ to $140^{\circ} \mathrm{W}$ and then weakens toward $170^{\circ} \mathrm{E}$, where it turns north and merges with the NECC. 
(a) No. of surface drifters released

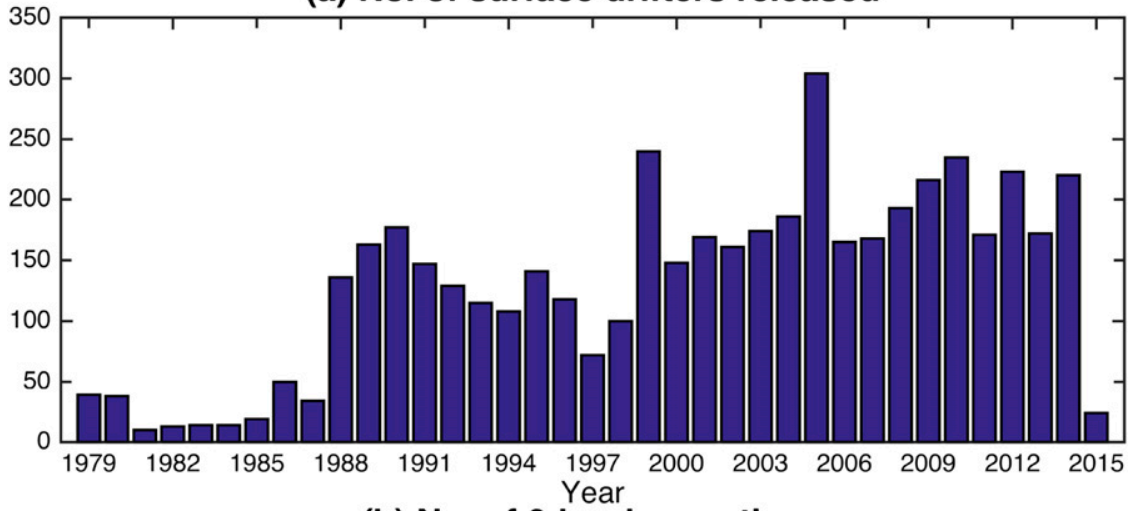

(b) No. of 6-hr observations

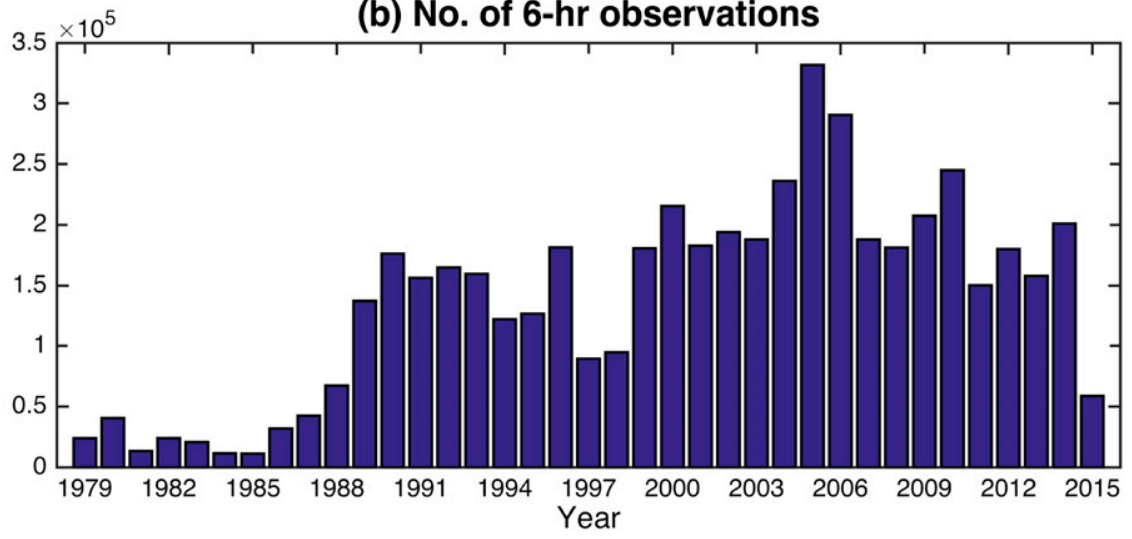

FIG. 2. (a) Total number of surface drifters released in the TPO. (b) Total number of surface drifter observations at 6-h intervals each year during 1979-2015 in the TPO.

The SECs maintains its strength farther west, from the eastern to the central Pacific, and shifts northward from $4.5^{\circ} \mathrm{S}$ at $120^{\circ} \mathrm{W}$ to $2.5^{\circ} \mathrm{S}$ at $170^{\circ} \mathrm{W}$. North of the SECn, the eastward NECC builds its strength in the western Pacific. The NECC shifts northward from $5^{\circ} \mathrm{N}$ at $140^{\circ} \mathrm{E}$ to $8.5^{\circ} \mathrm{N}$ at $120^{\circ} \mathrm{W}$, subsequently decelerates and shifts southward, and rebuilds its strength gradually and shifts north at $110^{\circ} \mathrm{W}$. Finally, it shifts southward at approximately $90^{\circ} \mathrm{W}$. The spatial distributions of the SEC and the NECC resulting from Lagrangian surface drifters are consistent with the results shown by other measurements (Johnson et al. 2002; Talley et al. 2011).

The TIVs can affect large-scale circulation by driving lateral mixing (Hansen and Paul 1984; Jochum et al. 2007; Menkes et al. 2006) and vertical exchange (Holmes and Thomas 2015; Inoue et al. 2012; Moum et al. 2009) between the ocean surface and its interior (Holmes et al. 2014). Hansen et al. (1980) described large-scale, anticyclonic eddylike westward motions using Lagrangian drifting buoys. Legeckis et al. (1983) created a schematic representation of the TIVs following Hansen et al. (1980). Later studies revealed the westward propagation of the TIVs between $4.4^{\circ}$ and $7^{\circ} \mathrm{N}$ based on satellite observations, a few Lagrangian surface drifters, and numerical models (Malardé et al. 1987; Flament et al. 1996; Weidman et al. 1999). Based on a numerical model, Ubelmann and Fu (2011) showed that the TIVs have a strong annual cycle with maximum presence from September to March, except during strong El Niño years, when the number of TIVs becomes very low. However, former studies of the TIVs are mainly based on a few in situ observations and numerical models, and the spatial distribution and temporal variation of the TIVs still need to be studied thoroughly as the dramatic increase of in situ observations in recent years and the advances of automatic eddy detection methods. Furthermore, the role of latitudinal shear in modulating annual and interannual variations of the TIVs remains to be studied in detail.

The Lagrangian surface drifter observations in the TPO started in 1979 (Fig. 2), and the numbers of surface drifters (Figs. 2a,b) and 6-h observations (Fig. 2c) have increased dramatically since 1989. Lagrangian surface drifters offer an opportunity to study the TIVs in detail as the recirculating velocity character of the TIVs causes easily identifiable loops in the drifter trajectories. 
(a) Cyclonic and Anticyclonic Eddies ( $r=10 \mathrm{~km})$
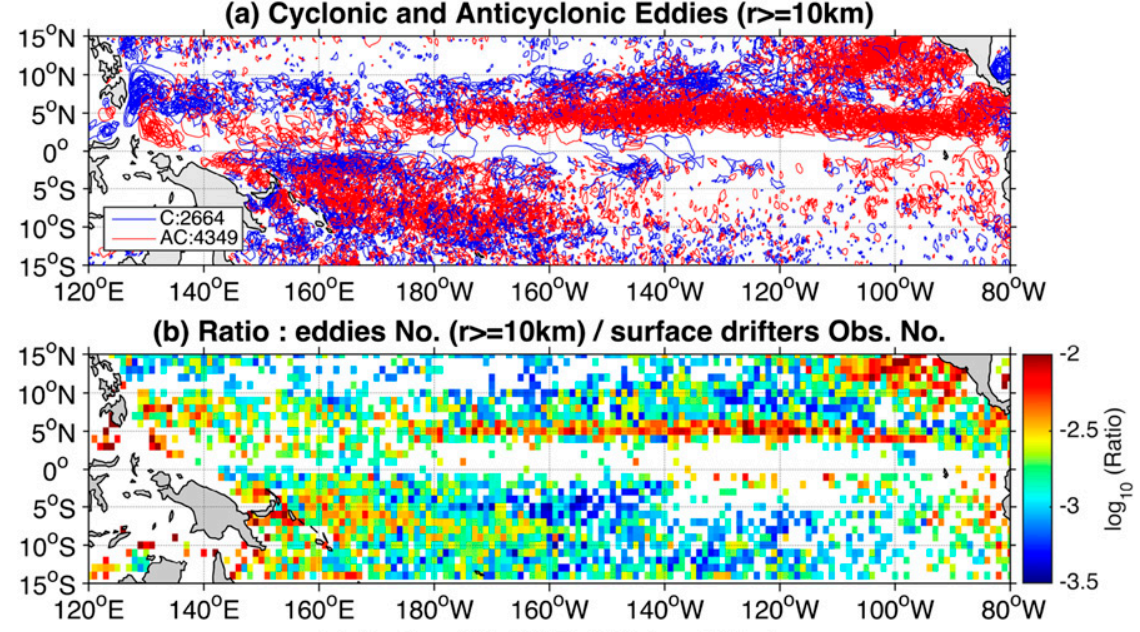

(c) Ratio: $A E /(A E+C E)(r>=10 \mathrm{~km})$

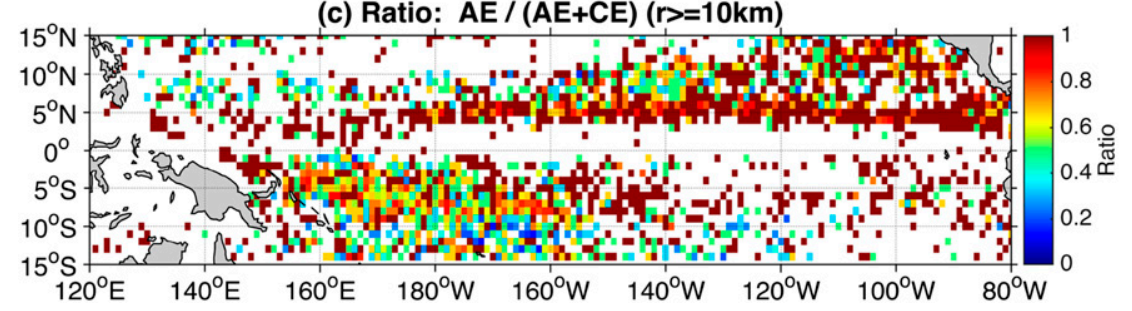

FIG. 3. (a) Distributions of cyclonic and anticyclonic eddies with radii $\geq 10 \mathrm{~km}$ detected from drifters in the TPO. The number of cyclonic (C) and anticyclonic (AC) eddies is indicated in the inset. (b) Ratio of the number of eddies with radii $\geq 10 \mathrm{~km}$ to the number of surface drifter 6-h observations in $1^{\circ} \times 1^{\circ}$ bins. (c) Ratio of the number of anticyclonic eddies (AEs) to all cyclonic eddies (CEs) and AEs with radii $\geq 10 \mathrm{~km}$ in $1^{\circ} \times 1^{\circ}$ bins.

The present study reveals the spatial distribution of mesoscale eddies in the TPO using Lagrangian surface drifters and focuses on the annual and interannual variations of the TIVs in the EETPO, as well as their dynamic mechanism.

The paper is structured as follows. Section 2 describes the data and method. Section 3 presents the spatial character and temporal variability of mesoscale eddies including the TIVs and the dynamic mechanism. Section 4 presents the summary and discussion.

\section{Data and methods}

The Lagrangian surface drifters used here were obtained from the National Oceanic and Atmospheric Administration's (NOAA's) Global Drifter Program, which has its Drifter Data Assembly Center at the Atlantic Oceanographic and Meteorological Laboratory (Lumpkin and Pazos 2007). The raw data of surface drifters are quality controlled and interpolated to uniform 6-h intervals through a kriging procedure (Hansen and Poulain 1996) by the Drifter Data Assembly Center. The surface drifters have their drogues centered at a depth of $15 \mathrm{~m}$, and all surface drifters, including undrogued drifters, are used in this study. Eddies detected from all surface drifters have similar spatial distribution and temporal variations to those detected from drogued drifters only (data not shown). We also used the climatological surface current derived from the drifter observations, gridded at a resolution of $0.5^{\circ} \times 0.5^{\circ}$ (Lumpkin and Johnson 2013). There are 5212 Lagrangian surface drifters released in the TPO during 1979-2015, and their spatial distribution is not uniform. Although most Lagrangian surface drifters were released along the equatorial region (dots in Fig. 1c), the number of surface drifter 6-h observations is sparse in the equatorial region because of upwelling and surface divergence; moreover, Lagrangian surface drifters tend to converge in the northeast and southwest TPO (shaded in Fig. 1c), carried by ocean surface currents.

The Niño-3.4 index is calculated via NOAA Optimum Interpolation Sea Surface Temperature (OISST) analysis by averaging the sea surface temperature (SST) anomaly in the region of $5^{\circ} \mathrm{S}-5^{\circ} \mathrm{N}, 170^{\circ}-120^{\circ} \mathrm{W}$ (Trenberth et al. 2002).

The near-real-time Ocean Surface Current Analyses Real-time (OSCAR), which has $1 / 3^{\circ}$ resolution derived from satellite observations (Bonjean and Lagerloef 2002), is used. OSCAR provides time means of zonal and meridional currents and estimates the zonal 
(a) Cyclonic and Anticyclonic Eddies ( $r=100 \mathrm{~km})$

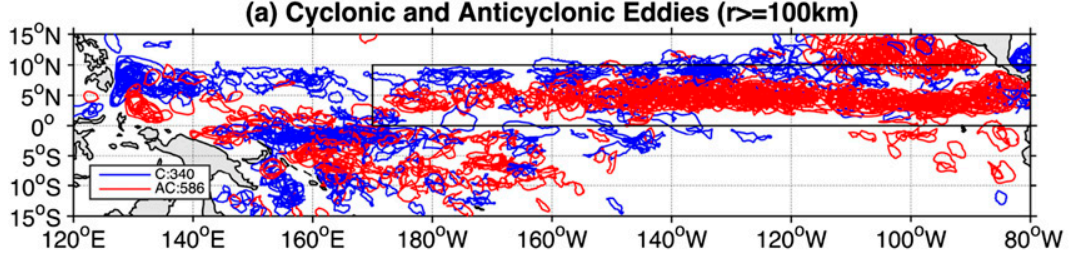

(b) Number of eddies ( $r=100 \mathrm{~km}$ )

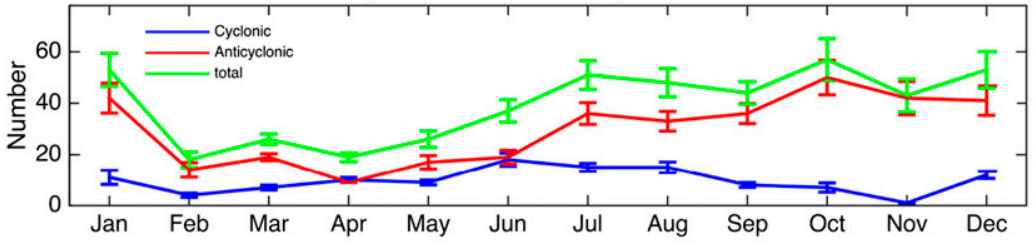

(c) Number of CE (r>=100km)

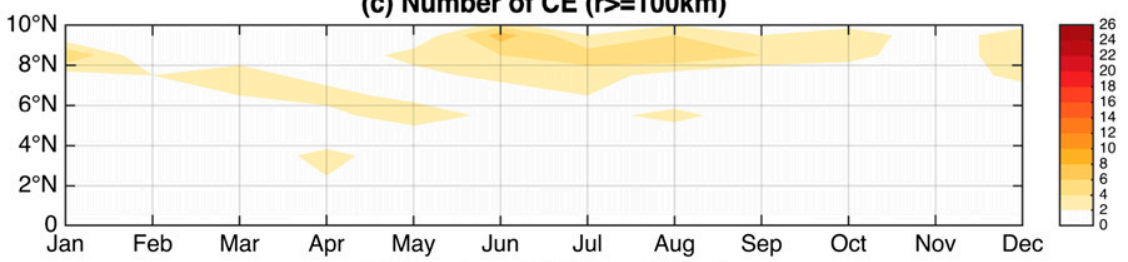

(d) Number of $A E(r>=100 \mathrm{~km})$

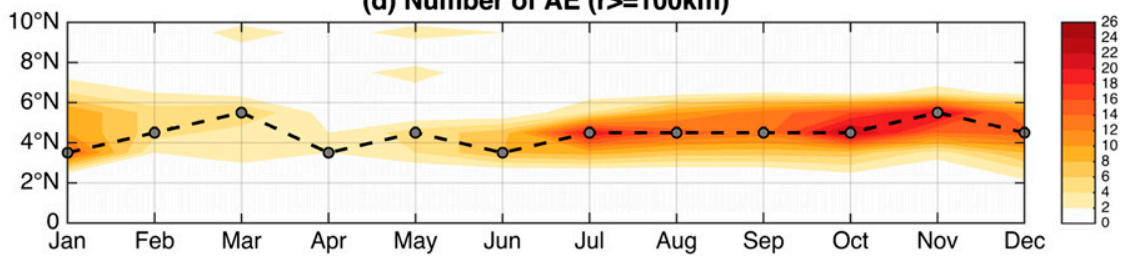

FIG. 4. (a) Distributions of cyclonic and anticyclonic eddies with radii $\geq 100 \mathrm{~km}$ detected from drifters in the TPO $\left(15^{\circ} \mathrm{S}-15^{\circ} \mathrm{N}, 120^{\circ} \mathrm{E}-80^{\circ} \mathrm{W}\right)$. The number of cyclonic (C) and anticyclonic (AC) eddies is indicated in the inset. (b) Number of eddies with radii $\geq 100 \mathrm{~km}$ in the EETPO $\left(0^{\circ}-10^{\circ} \mathrm{N}, 170^{\circ} \mathrm{E}-80^{\circ} \mathrm{W}\right.$, indicated by the rectangular black box in Fig. $\left.4 \mathrm{a}\right)$ region as a function of the calendar month for cyclonic (blue), anticyclonic (red), and both types of eddies (green). The bars indicate the standard error in the eddy number estimates. (c) Number of cyclonic eddies with radii $\geq 100 \mathrm{~km}$ in the EETPO region. The contour interval is 2. (d) As in (c), but for anticyclonic eddies. The black line represents the latitude at which the maximum number of anticyclonic eddies with radii $\geq 100 \mathrm{~km}$ occurs in the EETPO region.

current variations at seasonal and interannual time scales accurately in the near-equatorial region (Johnson et al. 2007).

The high eddy kinetic energy (EKE; $\mathrm{cm}^{2} \mathrm{~s}^{-2}$ ) from surface drifters (Lumpkin and Johnson 2013) in the TPO appears mainly along the equatorial band (Fig. 1d). EKE is calculated as follows: EKE $=(1 / 2)\left(u^{\prime 2}+v^{\prime 2}\right)$, where $u^{\prime 2}$ and $v^{\prime 2}$ are the zonal and meridional velocity variance, respectively; $u^{\prime}=u-U$ and $v^{\prime}=v-U$, where $u$ and $v$ are zonal and meridional drifter speeds, $U$ and $V$ are seasonal mean zonal and meridional drifter speeds mapped in elliptical bins of constant area $\pi \times\left(2^{\circ}\right)^{2}$ (Lumpkin and Johnson 2013). In the eastern Pacific Ocean, the high EKE occurs along a zonal band centered approximately along $3^{\circ} \mathrm{N}$ from $90^{\circ}$ to $150^{\circ} \mathrm{W}$; the band shifts southward along the equator from $150^{\circ} \mathrm{W}$ to $140^{\circ} \mathrm{E}$ and swings northward farther west.
The geometric method used to identify eddies from the trajectories of Lagrangian surface drifters has been developed and extensively used in many regions (Lankhorst 2006; Li et al. 2011; Dong et al. 2011; Zheng et al. 2015). In this study, we utilize the geometric method of Li et al. (2011) to identify eddies. This method can identify eddies automatically and reduce human error and bias associated with traditional manual eddy identification (Shoosmith et al. 2005). When a drifter is captured by an eddy, it will move in loops (Flament et al. 2001) before being ejected. Therefore, eddy identification is reduced to identifying loops within a trajectory. A loop is defined by a closed trajectory curve, and loops are combined into eddies according to their polarity and center distance. The loop center is calculated by averaging the trajectories' positions in the loop, and the loop radius is derived by averaging the distance between 
(a) Center of TIVs (anticyclonic eddies with $\mathrm{r}=100 \mathrm{~km}$ )

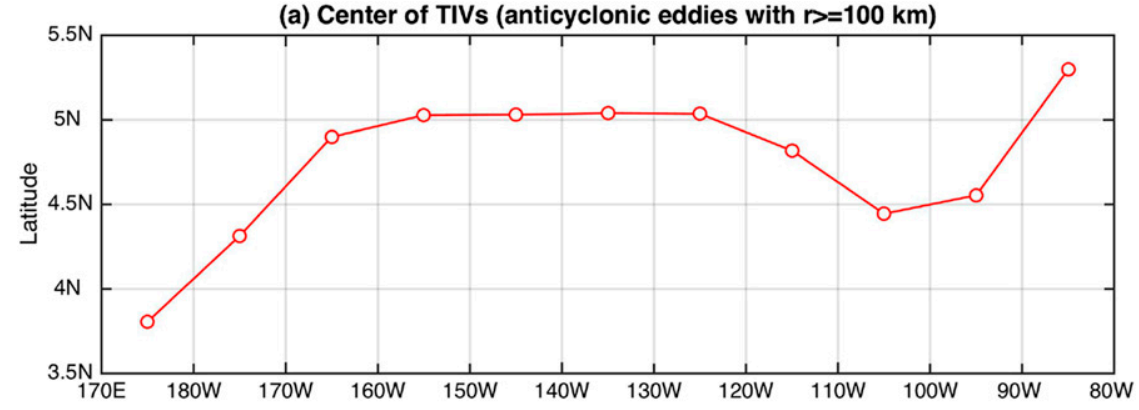

(b) Number of TIVs (anticyclonic eddies with $r>=100 \mathrm{~km}$ )

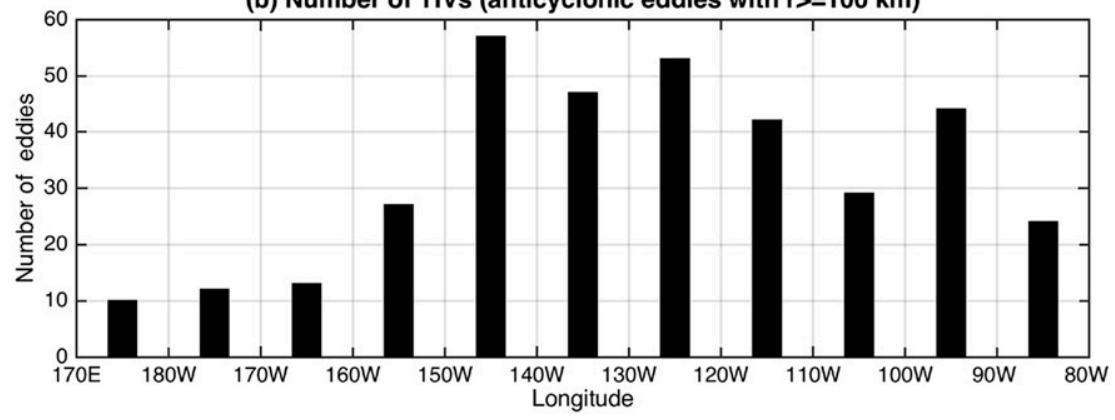

FIG. 5. (a) Center of anticyclonic eddies with radii $\geq 100 \mathrm{~km}$ as a function of longitude in a $10^{\circ}$ interval in the EETPO region. (b) Number of anticyclonic eddies with radii $\geq 100 \mathrm{~km}$ as a function of longitude in $10^{\circ}$ intervals in the EETPO region.

trajectory positions and the loop center. The eddy radius (center) can then be determined by averaging the radii (center) of clustered loops. The eddy radius identified from a drifter is likely to be underestimated because the drifter may circle near the center of the eddy rather than along its edges. Meanwhile, high-frequency inertial oscillation and low-frequency basin-scale gyres may also form loops. Here, eddies are defined according to the period between the inertial and intraseasonal scales (90 days) (Zheng et al. 2015) to eliminate the effects of inertial oscillation and low-frequency basin-scale gyre. The inertial oscillation period $T$ is calculated as follows: $T=2 \pi / f$, where $f=2 \Omega \sin (\varphi), f$ is the Coriolis parameter, $\Omega$ is Earth's rotating frequency $\left(\Omega=2 \pi / 24 \mathrm{~h}=7.27 \times 10^{-5} \mathrm{~s}^{-1}\right)$, and $\varphi$ is the latitude of the eddy center. Eddies with periods smaller than the local inertial oscillation period or exceeding 90 days are excluded.

Based on the Lagrangian surface drifters, 42776 loops are detected in the TPO using the geometric method. Among them, 13725 are cyclonic loops and 29051 are anticyclonic loops. Combining them into eddies reveals 7013 mesoscale eddies, including 2664 cyclonic mesoscale eddies and 4349 anticyclonic mesoscale eddies. The cyclonic (anticyclonic) eddies exhibit counterclockwise (clockwise) rotation in the Northern Hemisphere and the reverse in the Southern Hemisphere. The mean radii are approximately $50 \mathrm{~km}$ for both cyclonic and anticyclonic mesoscale eddies. The spatial distribution of eddies (radius $r \geq 10 \mathrm{~km}$; Fig. 3a) detected from surface drifters does not match that of surface drifter observations (Fig. 1c); in particular, a high ratio (Fig. 3b) of eddies $(r \geq 10 \mathrm{~km})$ to surface drifter observations (Fig. 1c) is distributed in a band along $5^{\circ} \mathrm{N}$ with more anticyclonic eddies than cyclonic eddies (Fig. 3c). This suggests that the spatial distribution of eddies detected from surface drifters is not an artifact of spatial sampling biases.

\section{Results}

\section{a. Spatial distribution of mesoscale eddies in the TPO}

The spatial distribution of mesoscale eddies with radii $\geq 100 \mathrm{~km}$ is shown in Fig. 4a. The mesoscale eddies with radii $\geq 100 \mathrm{~km}$ exhibit an inhomogeneous spatial distribution in the TPO; a dense population of eddies is distributed in the northeast and southwest TPO, and very few eddies are detected in the southeast TPO despite relatively high numbers of Lagrangian surface drifter observations in this region (Fig. 1c). Therefore, the spatial distribution of mesoscale eddies with radii $\geq 100 \mathrm{~km}$ is not an artifact of spatial sampling biases. The mesoscale eddies with radii $<100 \mathrm{~km}$ have a spatial distribution (supplemental Fig. S1) comparable to that of the mesoscale eddies with radii $\geq 100 \mathrm{~km}$. 
(a) Number of eddies ( $>=10 \mathrm{~km}$ )
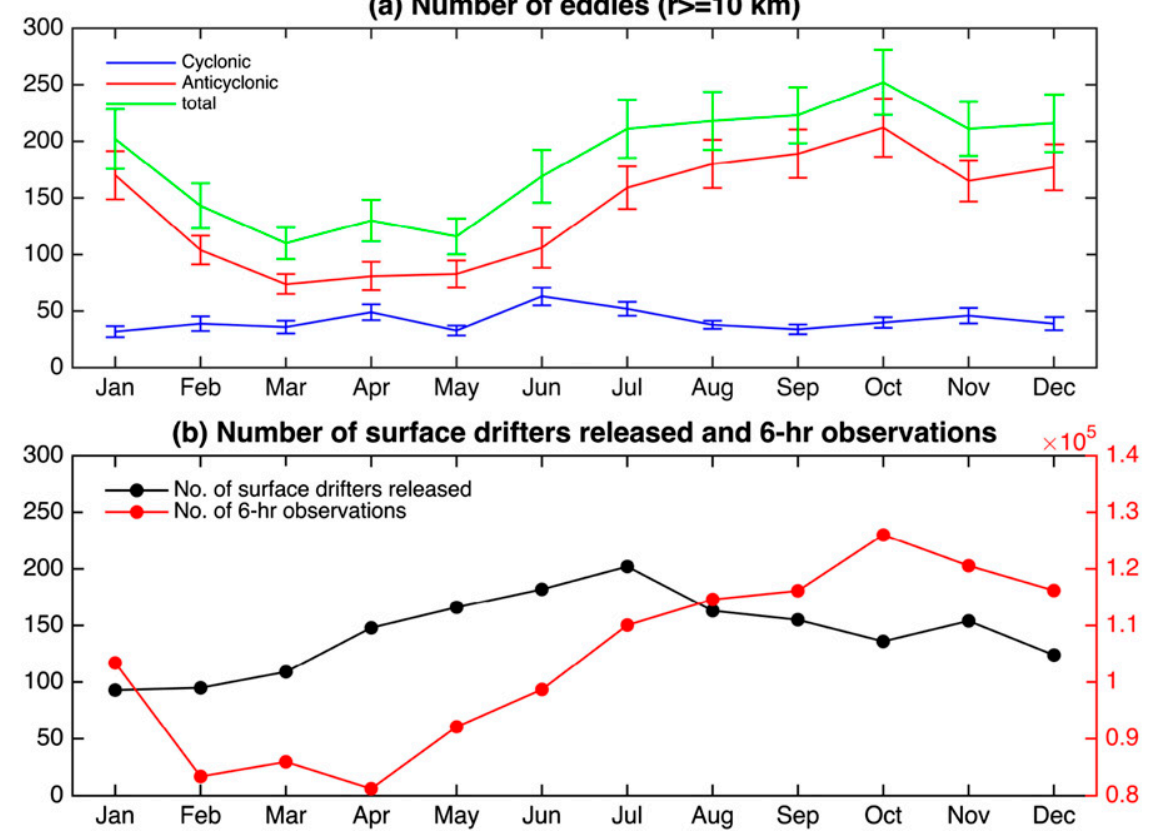

FIG. 6. (a) Number of eddies with radii $\geq 10 \mathrm{~km}$ in the EETPO region as a function of calendar months for cyclonic (blue), anticyclonic (red), and both types of eddies (green). The bars indicate the standard error in the eddy number estimates. (b) Total number of surface drifters (black) released in the EETPO and total number of surface drifter observations at 6-h intervals (red) in each climatological calendar month in the EETPO.

In the northwest TPO, the mean radius of the identified Mindanao eddies (MEs) is $190 \mathrm{~km}$ and is centered at $7.6^{\circ} \mathrm{N}, 129.7^{\circ} \mathrm{E}$, whereas the mean radius of the identified Halmahera eddies (HEs) is $157 \mathrm{~km}$ and is centered at $3.4^{\circ} \mathrm{N}, 130.8^{\circ} \mathrm{E}$. MEs are observed 17 times and are not detected in some months (January, May, July, and November). According to the study of Kashino et al. (2013), the MEs are not quasi-stationary eddies. In the southwest TPO, mesoscale eddies are mainly detected between $140^{\circ} \mathrm{E}$ and $150^{\circ} \mathrm{W}$. The mean radius of cyclonic (anticyclonic) mesoscale eddies with radii $\geq 10 \mathrm{~km}$ is $46 \mathrm{~km}(40 \mathrm{~km})$ in the region of $15^{\circ} \mathrm{S}-0^{\circ}, 140^{\circ} \mathrm{E}-150^{\circ} \mathrm{W}$. The number of surface drifters (supplemental Fig. S2a) and 6-h observations (supplemental Fig. S2b) are high in austral summer and low in austral autumn. In contrast, the occurrence of eddies exhibits different seasonal variability (supplemental Fig. S3), with more eddies in austral summer and autumn and fewer in austral winter and spring. Thus, the seasonal variation of eddies detected from surface drifters in the southwest TPO is not an artifact of temporal sampling biases.

In the northeast TPO, a group of anticyclonic (red trajectories in Fig. 4a) eddies is centered at approximately $12.5^{\circ} \mathrm{N}$ from $90^{\circ}$ to $120^{\circ} \mathrm{W}$. These eddies likely originate from the Gulfs of Tehuantepec and Papagayo. The anticyclonic eddies with lifetimes exceeding 6 weeks are generated from low-frequency wind and boundary forcing (Liang et al. 2012) and have significant interannual variability in eddy activity, with more (fewer) eddies, more intense (weaker) eddies, and a longer (shorter) eddy season during El Niño (La Niña) years (Palacios and Bograd 2005).

South of $10^{\circ} \mathrm{N}$, in the EETPO (rectangular black box in Fig. 4a), a group of anticyclonic eddies with radii $\geq$ $100 \mathrm{~km}$ (viz., the TIVs) are distributed along a band at $5^{\circ} \mathrm{N}$ and have a similar spatial distribution to that identified by Lumpkin (2016), who used stricter criteria to identify loops with at least two orbits in Lagrangian trajectory data. The mean radius of the TIVs identified from surface drifters in the EETPO (supplemental Fig. S4) is $154 \mathrm{~km}$, consistent with previous studies, which indicated that the typical diameter of the TIVs is $300-500 \mathrm{~km}$ (Flament et al. 1996; Legeckis et al. 2004; Weidman et al. 1999). The mean period of the TIVs identified from surface drifters is 34 days, consistent with Ubelmann and Fu (2011), who suggested that the period of the TIVs is $30-35$ days based on a numerical model. The center latitude and number of the TIVs vary with the longitude (Fig. 5). There are more TIVs along $5^{\circ} \mathrm{N}$ detected in the central EETPO region and fewer TIVs in the western and eastern ends of the EETPO (Fig. 5b). The center 
(a) Niño 3.4

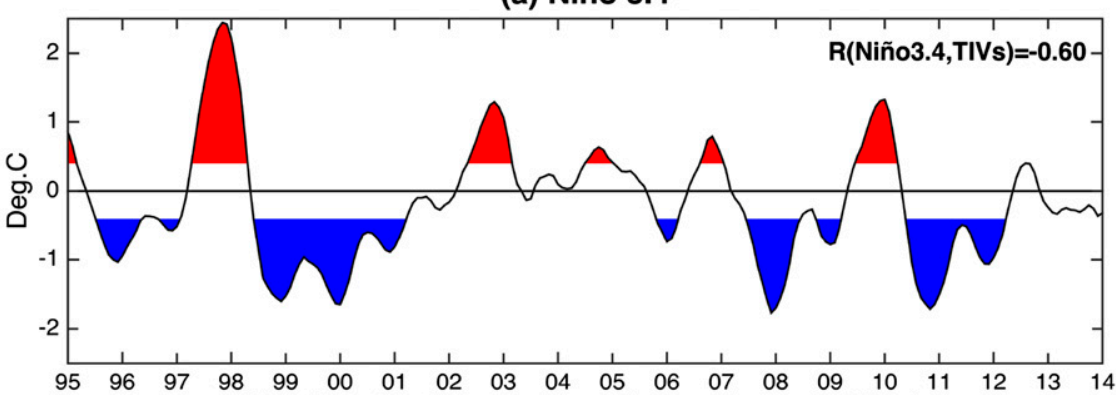

(b) TIVs (anticyclonic eddies with $r=100 \mathrm{~km}$ )

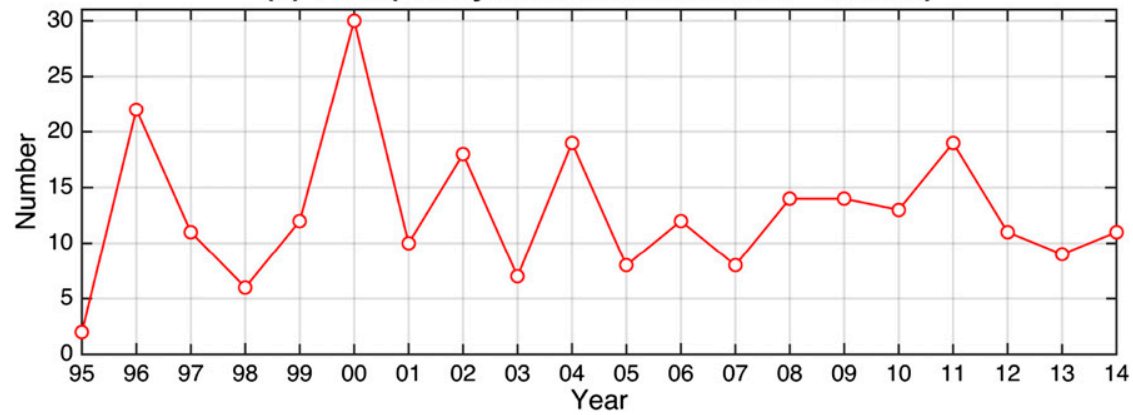

FIG. 7. (a) Time series plots of the Niño-3.4 indices as 5-month running means using OISST data. Values above a threshold of $\pm 0.4^{\circ} \mathrm{C}$ for Niño-3.4 are stippled to indicate ENSO events. $R$ represents the correlation between Niño-3.4 indices and the number of TIVs and is significant at the $95 \%$ significance level. (b) Number of anticyclonic eddies with radii $\geq 100 \mathrm{~km}$ in the EETPO region during the ENSO year (from July to the following June).

latitude of the TIVs tilt equatorward from east to west (Fig. 5a), consistent with previous studies of anticyclonic eddies off the tropical regions (Chelton et al. 2007; Morrow et al. 2004). In the EETPO region, the number of mesoscale eddies with radii $\geq 100 \mathrm{~km}$ is 475 , and the ratio of the TIVs (358) to cyclonic eddies (117) is approximately 3 to 1 . The mean radius and period for cyclonic eddies with radii $\geq 100 \mathrm{~km}$ are $160 \mathrm{~km}$ and 55 days. The mean tangential velocities of cyclonic eddies with radii $\geq 100 \mathrm{~km}$ and TIVs are approximately 0.22 and $0.46 \mathrm{~m} \mathrm{~s}^{-1}$, respectively.

\section{b. Temporal variability in the EETPO region}

In the EETPO region, the occurrence of the TIVs exhibits pronounced seasonal variations (red line in Fig. 4b), with fewer eddies from February to June and more eddies from July to January. Because the TIWs are detectable in the SST during July-November (Willett et al. 2006; Contreras 2002), it suggests that the TIVs persist 2 months longer than the TIWs. The annual cycle of the TIVs identified from surface drifters has some discrepancy with the study of Ubelmann and $\mathrm{Fu}$ (2011), who indicated that the TIVs have a strong annual cycle with maximum presence from September to March based on a numerical model. If anticyclonic eddies with radii of $10-100 \mathrm{~km}$ are included, the number of anticyclonic eddies (Fig. 6a) shows a seasonal cycle similar to that of the TIVs. The number of TIVs reaches a minimum in April and a maximum in October. More surface drifters are released in the EETPO in boreal summer, with the maximum number in July (Fig. 6b). The number of 6-h observations (Fig. 6b) is maximized in October, with a standard deviation of $1.55 \times 10^{4}$ and a mean value of $1.04 \times 10^{5}$. Although the seasonal variations of the numbers of TIVs are in phase with the numbers of 6-h observations, the number of TIVs in SeptemberOctober is more than twice that in March-April, indicating that the seasonal variations of the TIVs are not an artifact of temporal sampling biases. The mean latitudinal center of the TIVs and cyclonic eddies with radii $\geq 100 \mathrm{~km}$ are $4.9^{\circ}$ and $7.0^{\circ} \mathrm{N}$, respectively; namely, the TIVs tend to be located to the south of cyclonic eddies (Fig. 4a). The seasonal variation in the number of eddies in the EETPO also reveals that cyclonic eddies with radii $\geq 100 \mathrm{~km}$ spread farther north, with the maximum number found near $9.5^{\circ} \mathrm{N}$ in June (Fig. 4c), whereas the TIVs tend to appear farther south along $3^{\circ}-6^{\circ} \mathrm{N}$ (Fig. $4 \mathrm{~d}$ ).

In addition to seasonal variations, the number of TIVs also exhibits interannual variability (Fig. 7) associated with El Niño-Southern Oscillation (ENSO), and the low correlation $(R=0.33)$ between the numbers of TIVs and 
(a) No. of surface drifters released

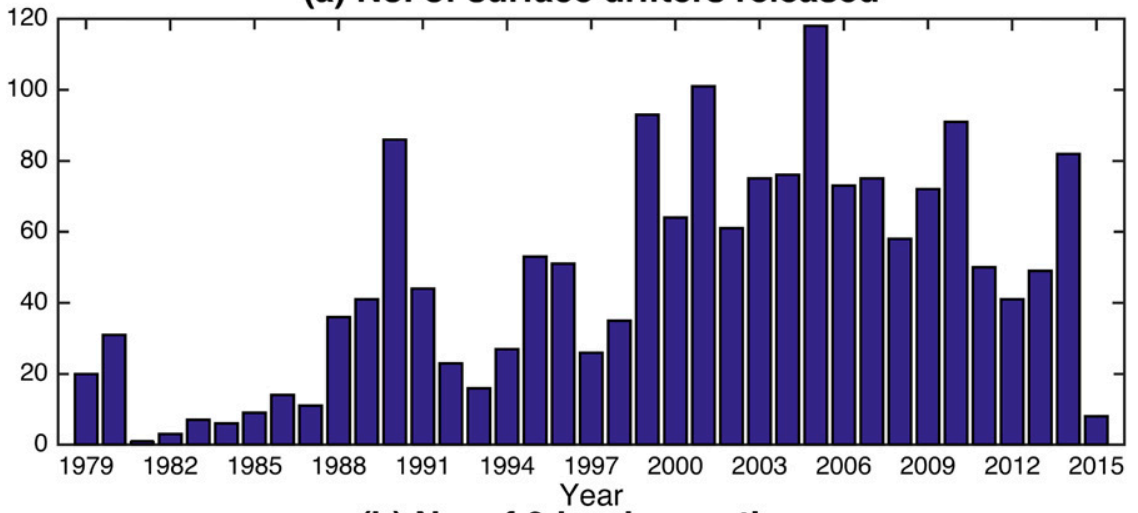

(b) No. of 6-hr observations

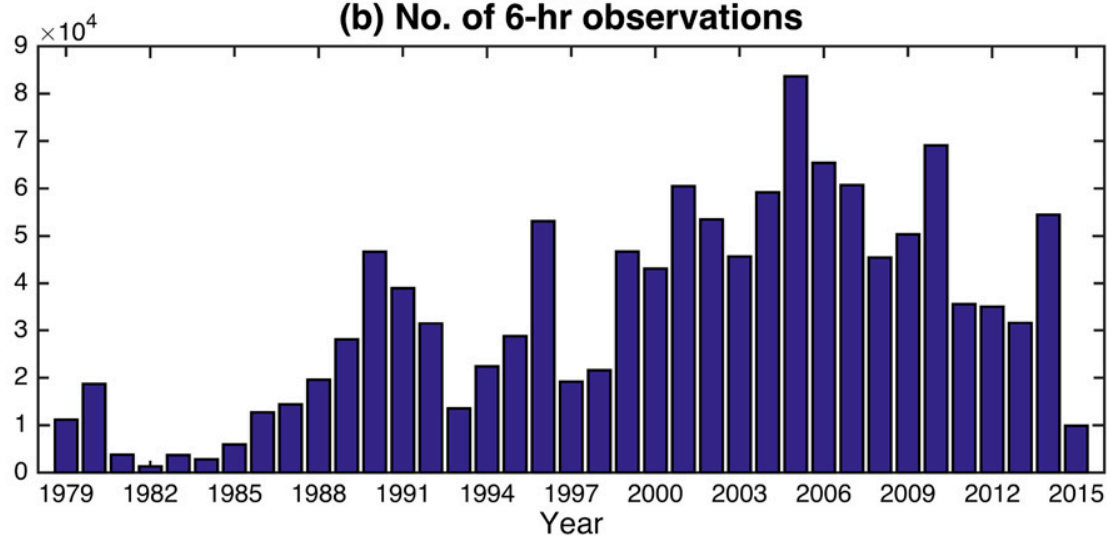

FIG. 8. (a) Interannual variation of surface drifters released in the EETPO. (b) Interannual variation of surface drifter 6-h observations in the EETPO.

surface drifter 6-h observations (Fig. 8b) during 19952014 suggests that the interannual variations of the TIVs are not an artifact of temporal sampling biases. During El Niño events (Fig. 7a), such as 1997/98, the number of TIVs (Fig. 7b) is much lower than that during the subsequent La Niña events, such as 1999/2000. The modeling study of Ubelmann and Fu (2011) also indicated that hardly any large vortex structures could be detected during the 1997/98 El Niño. The number of TIVs is correlated with the Niño-3.4 index $(R=-0.60$, significant at the 95\% significance level) during 1995-2014, when there are sufficient surface drifter observations in the EETPO (Fig. 8).

\section{c. Forcing mechanisms}

Previous studies show that the barotropic shear between the westward SEC and eastward NECC is the primary energy source for the TIWs (Cox 1980; Kennan and Flament 2000; Lyman et al. 2005; Luther and Johnson 1990; Philander 1978), and the TIVs should share a similar energy source. The seasonal variations of the TIVs along a band at $5^{\circ} \mathrm{N}$, which was identified based on Lagrangian surface drifters, tend to be consistent with this theory. The western boundary of high TIV activities in the EETPO is located at approximately $170^{\circ} \mathrm{E}$, where the SEC weakens and steers northward (Fig. 1b). Moreover, the seasonal variations in the number of eddies tend to follow the seasonal variations in the latitudinal shear between the SEC and NECC. The seasonal variations in the zonal mean $\left(170^{\circ} \mathrm{E}-80^{\circ} \mathrm{W}\right)$ velocity based on the surface drifter velocity (Lumpkin and Johnson 2013) indicate that the westward SEC reaches its maximum in January-February $\left(-0.51 \mathrm{~m} \mathrm{~s}^{-1}\right)$ and August-September $\left(-0.63 \mathrm{~m} \mathrm{~s}^{-1}\right)$ (Fig. 9a). The mean velocity of the SEC is $-0.44 \mathrm{~m} \mathrm{~s}^{-1}$, with a standard deviation of $0.14 \mathrm{~m} \mathrm{~s}^{-1}$, whereas the mean latitudinal center of the SEC is $1.96^{\circ} \mathrm{N}$, with a standard deviation of $0.33^{\circ}$. In contrast, the eastward NECC reaches its maximum in October $\left(0.41 \mathrm{~m} \mathrm{~s}^{-1}\right)$ at $7.5^{\circ} \mathrm{N}$ (Fig. 9a). The mean velocity of the NECC is $0.29 \mathrm{~m} \mathrm{~s}^{-1}$, with a standard deviation of $0.12 \mathrm{~m} \mathrm{~s}^{-1}$, and the mean latitudinal center of the NECC is $6.58^{\circ} \mathrm{N}$, with a standard deviation of $0.51^{\circ}$. The gradient of the zonal mean velocity shears between the SEC and NECC is maximized in AugustSeptember (Fig. 9b), in good agreement with the annual variations in the number of TIVs (Fig. 4b). 
(a) Velocity of zonal mean in $170^{\circ} \mathrm{E}-80^{\circ} \mathrm{W}$

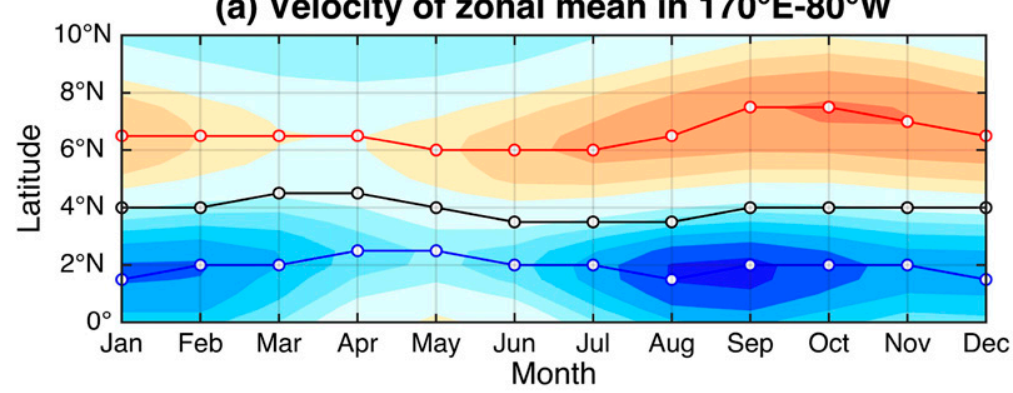

(b) Gradient

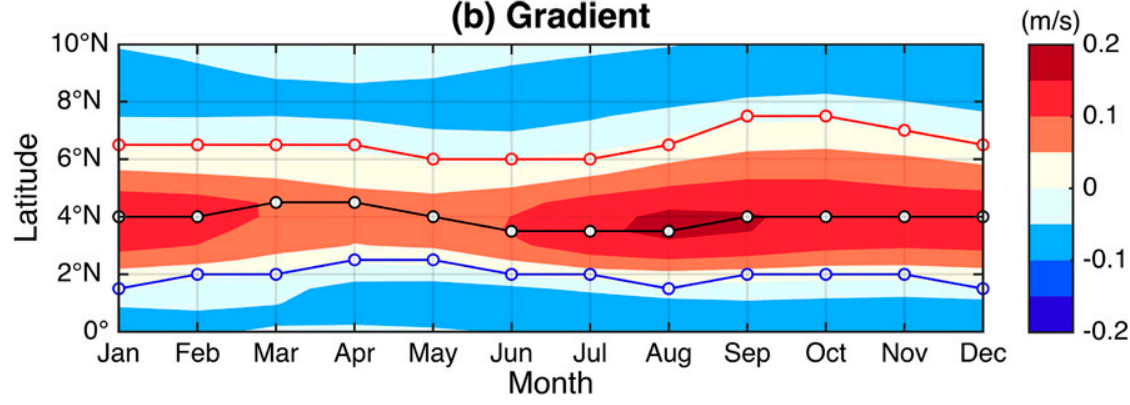

FIG. 9. (a) Velocity $\left(\mathrm{m} \mathrm{s}^{-1}\right)$ of the zonal mean in $170^{\circ} \mathrm{E}-80^{\circ} \mathrm{W}$ from surface drifters (Lumpkin and Johnson 2013) as a function of the calendar month. (b) Gradient of (a). The red line represents the latitude of the zonal mean velocity maximum, the blue line represents the latitude of the zonal mean velocity minimum, and the black line represents the latitude of the gradient maximum.
Here, we examine the relationship between the interannual variability of the latitudinal shear and the number of the TIVs. The SEC and NECC mainly occupy latitudes of $1^{\circ}-4.5^{\circ}$ and $5^{\circ}-8.5^{\circ} \mathrm{N}$ (Fig. 9a). Therefore, we calculate an SEC index from OSCAR monthly surface currents by averaging the zonal velocity in the regions of $1^{\circ}-4.5^{\circ} \mathrm{N}$ and $170^{\circ} \mathrm{E}-80^{\circ} \mathrm{W}$ and an NECC index in the regions of $5^{\circ}-8.5^{\circ} \mathrm{N}$ and $170^{\circ} \mathrm{E}-$ $80^{\circ} \mathrm{W}$ during 1995-2014. The SEC and the barotropic shear with the NECC are significantly correlated with the Niño-3.4 index, leading Niño-3.4 by 3 months, with correlation coefficients of 0.61 and -0.40 (significant at the $95 \%$ significance level; Fig. 10), respectively. Namely, during El Niño events, the westward SEC and its shear with NECC are weak, whereas during La Niña events, the westward SEC and its shear are strong because easterly trade winds strengthen and migrate westward (Johnson et al. 2002). The barotropic shear between the SEC and NECC leads the ENSO by 3 months, and ENSO events are phase locked during November-January (NDJ). Therefore, we examine the role of the ENSO in the interannual variation of the TIVs by compositing the surface current during El Niño and La Niña events in August-October (ASO), when the number of TIVs is high (Fig. 4b) and the barotropic shear is enhanced (Fig. 9b). We calculate the composites of the surface current in the EETPO region from August to October during El Niño events in 1997/98,
2002/03, 2004/05, 2006/07, and 2009/10 (Fig. 11a) and La Niña events in 1995/96, 1998/99, 1999/2000, 2000/01, 2007/08, 2010/11, and 2011/12 (Fig. 11b) and compare the results with the strong El Niño event in 1997/98 (Fig. 11c) and the subsequent La Niña event in 1999/2000 (Fig. 11d). The westward SEC almost vanishes during El Niño events (Fig. 11a), especially in the strong El Niño event in 1997/98 (Fig. 11c), causing weak shear between the SEC and NECC and thus a lower chance of generating the TIVs. Therefore, the number of TIVs is relatively low. In contrast, the SEC is significantly enhanced during La Niña events (Figs. 11b,d), causing strong shear between the SEC and NECC and favoring the development of the TIVs. Thus, the interannual variations of the TIVs are associated with the variation of latitudinal shear between the SEC and NECC modulated by ENSO.

\section{Summary and discussion}

In our study, the mesoscale eddies in the TPO are studied using Lagrangian surface drifters, with a focus on eddies with radii $\geq 100 \mathrm{~km}$ (i.e., the TIVs). Eddies exhibit high activity in the northeast and southwest TPO. The TIVs along a band at $5^{\circ} \mathrm{N}$ from $170^{\circ} \mathrm{E}$ to $80^{\circ} \mathrm{W}$ are studied in detail. Based on in situ observations, we reveal that the TIVs show seasonal variation corresponding to variation in the latitudinal velocity shear between the SEC and the NECC; namely, more TIVs 


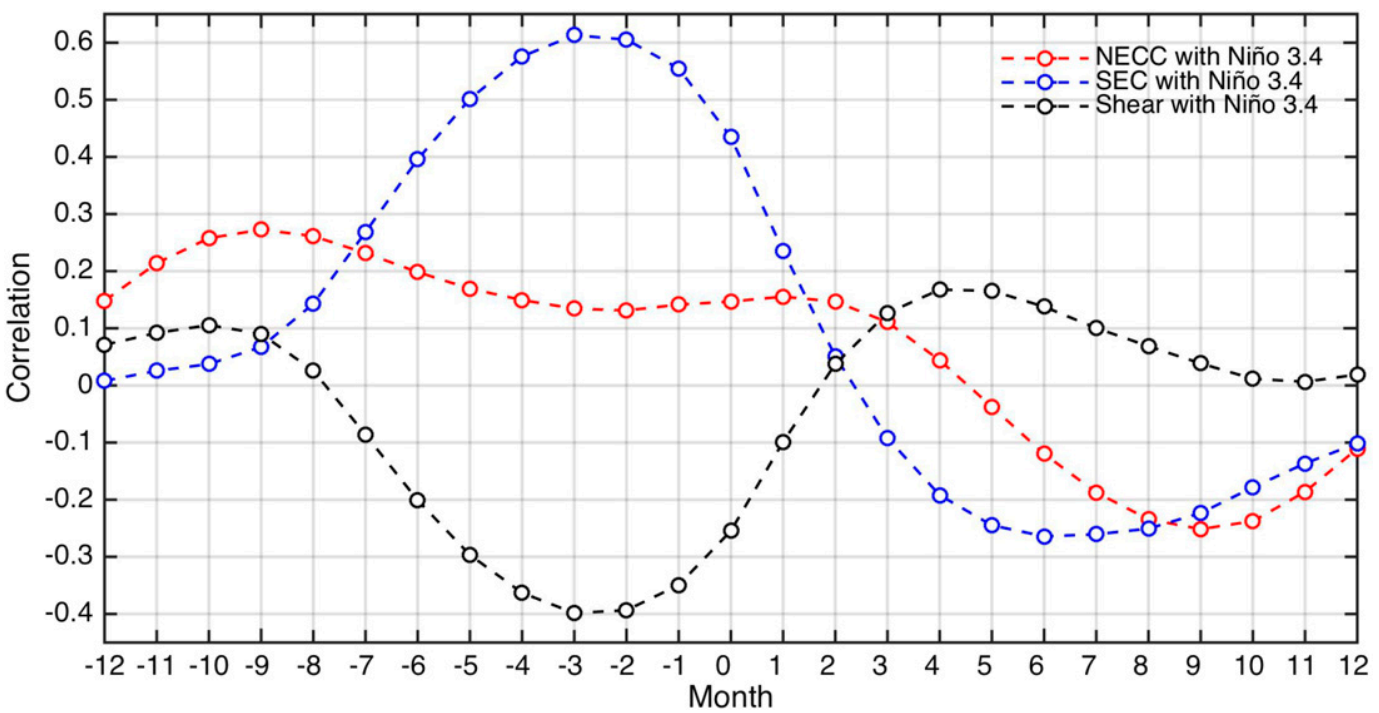

FIG. 10. Lead and lag correlation of the NECC (red), SEC (blue), and latitudinal shear (black) with the Niño 3.4 index. Negative values represent lead correlations, whereas positive values represent lag correlations. The latitudinal shear is defined as the NECC minus the SEC.

arise in the presence of enhanced velocity shear, and vice versa. At the interannual time scale, the variation of the TIVs is modulated by ENSO, and more TIVs are detected during La Niña events, whereas fewer are detected during El Niño events. The interannual variations of the TIV detections are closely related to the variations of the latitudinal shears between the SEC and the NECC. The relationship between the current shear

(a) EI Niño Events: ASO

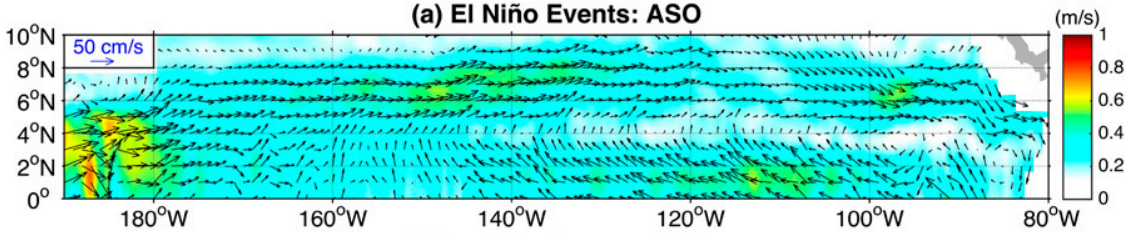

(b) La Niña Events: ASO

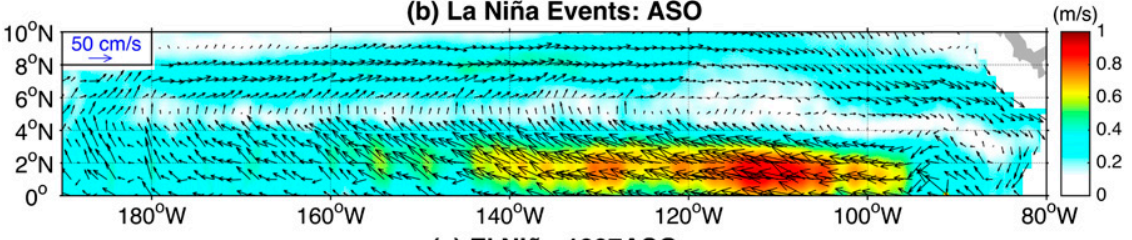

(c) El Niño 1997ASO

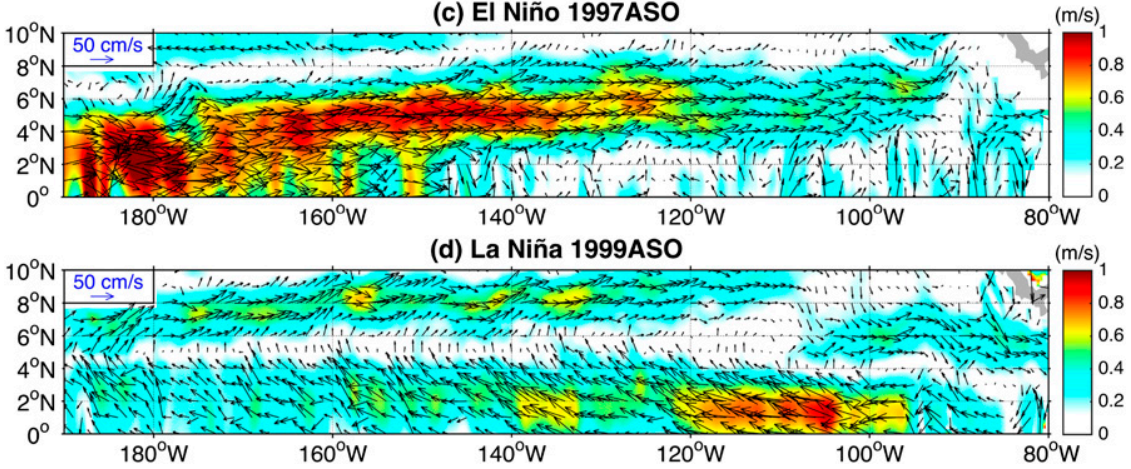

FIG. 11. Composites of the surface currents (vectors) from OSCAR in the EETPO in ASO during (a) El Niño events and (b) La Niña events during 1995-2014, (c) the strong El Niño event in 1997/98, and (d) the subsequent La Niña event in 1999/2000. Shaded color represents speed $\left(\mathrm{m} \mathrm{s}^{-1}\right)$. 


\section{(a) Zonal mean SST in $170^{\circ} \mathrm{E}-80^{\circ} \mathrm{W}$}

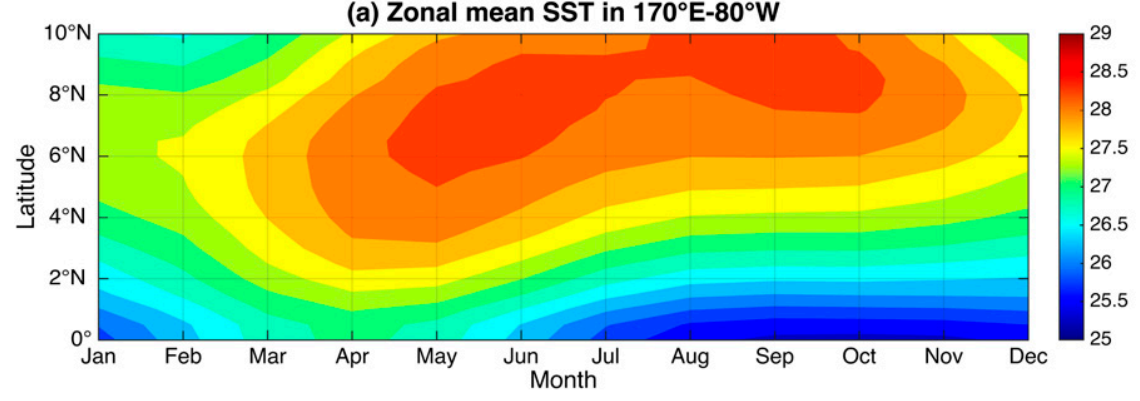

(b) Gradient

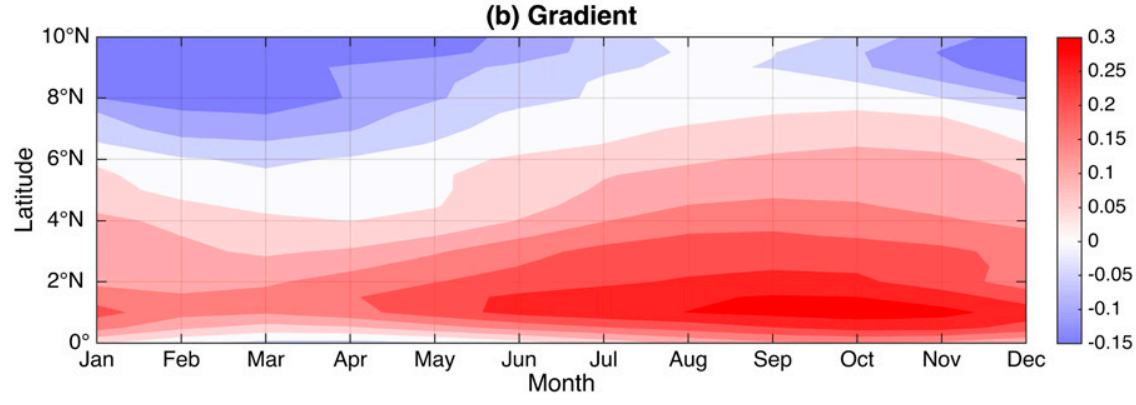

FIG. 12. (a) Zonal mean SST in $170^{\circ} \mathrm{E}-80^{\circ} \mathrm{W}$ from surface drifters (Lumpkin and Johnson 2013) as a function of the calendar month. (b) Gradient of (a).

and the TIVs suggests that barotropic instability is a key process to supply energy sources for the TIVs.

In addition to the barotropic instability, previous studies using numerical models showed that frontal instability (Cox 1980; Holmes et al. 2014; Masina et al. 1999; Proehl 1996) and baroclinic instability (Cox 1980; Masina et al. 1999) also contribute to the generation of TIWs and TIVs. The lateral gradient (Fig. 12b) of the (a) ORAS4 SEC

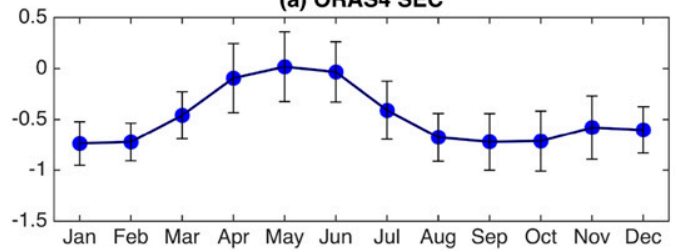

(b) ORAS4 EUC

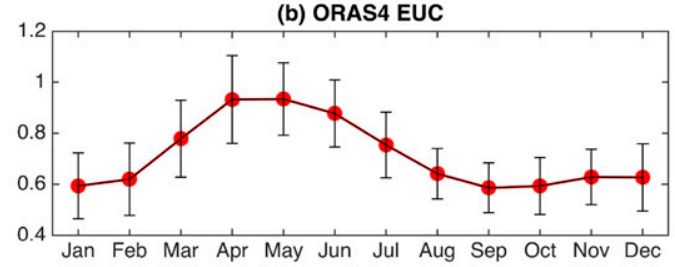

(c) ORAS4 Shear

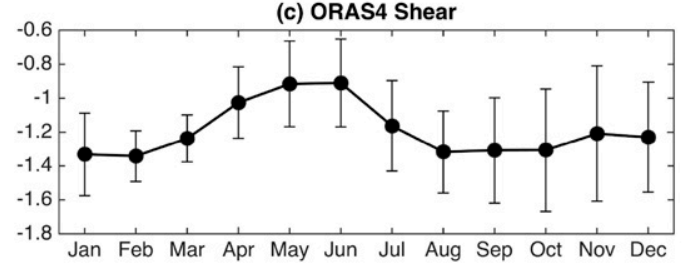

(d) OFES SEC

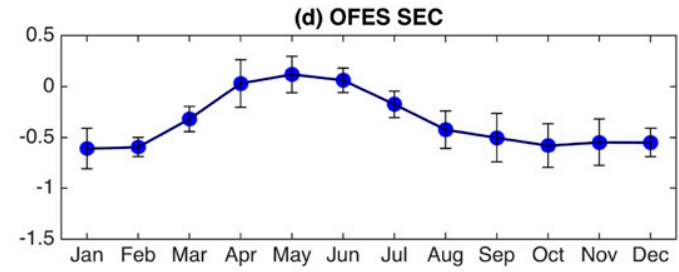

(e) OFES EUC
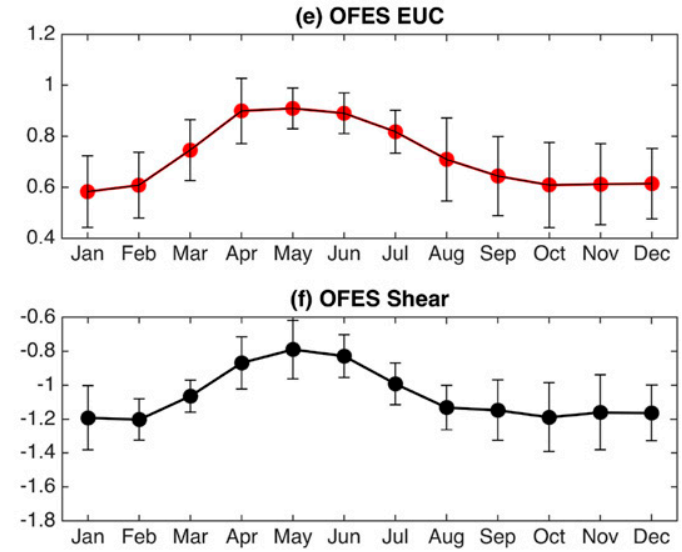

FIG. 13. Seasonal variability of (a) the SEC $\left(\mathrm{m} \mathrm{s}^{-1}\right)$ at the surface, (b) the EUC $\left(\mathrm{m} \mathrm{s}^{-1}\right.$; shown in supplemental Figs. S5 and S6), and (c) the shear between the SEC and EUC along $0.5^{\circ} \mathrm{N}$ from ORAS4 from January 1995 to December 2014; (d)-(f) as in (a)-(c), but for OFES from August 1999 to July 2009. Error bars indicate the standard deviation. 
zonal mean SST $\left(170^{\circ} \mathrm{E}-80^{\circ} \mathrm{W}\right.$; Fig. $\left.12 \mathrm{a}\right)$ exhibits a weak gradient in spring and a strong gradient in the other seasons between the equator and $6^{\circ} \mathrm{N}$. The strongest gradient is located at $1^{\circ} \mathrm{N}$. The seasonal variation of the SST gradient is similar to that of the number of TIVs (Fig. 4b); thus, front instability may still contribute to seasonal variation of TIVs in spite of a relatively weak gradient of the SST along $5^{\circ} \mathrm{N}$. The vertical shear between the SEC and the Equatorial Undercurrent (EUC) along $0.5^{\circ} \mathrm{N}$ is weak during May-July and is enhanced during August-February (Fig. 13), according to the European Centre for Medium-Range Weather Forecasts (ECMWF) Ocean Reanalysis System 4 (ORAS4; Balmaseda et al. 2013) and the eddy-resolving Ocean General Circulation Model (OGCM) for the Earth Simulator (OFES; Masumoto et al. 2004; Sasaki et al. 2008). Therefore, the three energy sources (i.e., barotropic, baroclinic, and frontal instabilities) vary concurrently and are related to the strength of the equatorial circulation. The contribution from baroclinic instability may require further study using a high-resolution numerical model.

Constrained by data availability, our study captures only the surface signature of the TIVs; the vertical characteristics of the TIVs are also very important and require further study. According to in situ observations, ENSO modulates the interannual variation of the TIVs. On the other hand, the TIVs could bring colder upwelled water northward on the western side and warmer water southward on the eastern side (Hansen and Paul 1984) and influence the heat (Hansen and Paul 1984; Lien et al. 2008; Menkes et al. 2006; Moum et al. 2013; $\mathrm{Yu}$ and Liu 2003) and momentum budgets in the equatorial Pacific (Brown et al. 2010; Qiao and Weisberg 1997), with potential implications for ENSO variability (Vialard et al. 2001; Yu and Liu 2003). The relationship between mesoscale eddies and ENSO variability may be crucial to the dynamics of ENSO and its regional impacts.

Acknowledgments. We thank Ruixin Huang of WHOI for useful discussions and comments. This study was supported by the Strategic Priority Research Program of the Chinese Academy of Sciences (XDA11010103), the Natural Science Foundation of China (41306018, 41525019, and 41521005), and the Open Project Program of State Key Laboratory of Tropical Oceanography (Grant LTOZZ1501), as well as the CAS/SAFEA International Partnership Program for Creative Research Teams. This work was finished during the visit of S. Zheng to CSIRO under the support of the State Administration of Foreign Experts Affairs of P.R. China and CAS. The observations of Lagrangian surface drifters were provided by the Atlantic
Oceanographic and Meteorological Laboratory (AOML; http://www.aoml.noaa.gov/envids/gld/index.php). The climatological surface current and eddy kinetic energy data were also obtained from AOML (http://www. aoml.noaa.gov/phod/dac/dac_meanvel.php). The OISST and Niño-3.4 indices were provided by the Ocean Observations Panel for Climate (http://ioc-goos-oopc.org/state of_the_ocean/sur/pac/nino3.4.php). The OSCAR data were provided by the National Oceanic and Atmospheric Administration (http://www.oscar.noaa.gov/index.html). The ORAS4 data were provided by the Asia-Pacific DataResearch Center (APDRC; http://apdrc.soest.hawaii. edu/datadoc/ecmwf_oras4.php). The OFES data were also provided by APDRC (http://apdrc.soest.hawaii.edu/ dods/iprc_esc/OfES).

\section{REFERENCES}

Balmaseda, M. A., K. Mogensen, and A. T. Weaver, 2013: Evaluation of the ECMWF Ocean Reanalysis System ORAS4. Quart. J. Roy. Meteor. Soc., 139, 1132-1161, doi:10.1002/qj.2063.

Baturin, N. G., and P. P. Niiler, 1997: Effects of instability waves in the mixed layer of the equatorial Pacific. J. Geophys. Res., 102, 27 771-27 793, doi:10.1029/97JC02455.

Bonjean, F., and G. S. E. Lagerloef, 2002: Diagnostic model and analysis of the surface currents in the tropical Pacific Ocean. J. Phys. Oceanogr., 32, 2938-2954, doi:10.1175/1520-0485(2002)032<2938: DMAAOT $>2.0 . \mathrm{CO} ; 2$.

Brown, J. N., J. S. Godfrey, and S. E. Wijffels, 2010: Nonlinear effects of tropical instability waves on the equatorial Pacific circulation. J. Phys. Oceanogr., 40, 381-393, doi:10.1175/ 2009JPO3963.1.

Chelton, D. B., M. G. Schlax, R. M. Samelson, and R. A. de Szoeke, 2007: Global observations of large oceanic eddies. Geophys. Res. Lett., 34, L15606, doi:10.1029/2007GL030812.

Contreras, R. F., 2002: Long-term observations of tropical instability waves. J. Phys. Oceanogr., 32, 2715-2722, doi:10.1175/ 1520-0485-32.9.2715.

Cox, M. D., 1980: Generation and propagation of 30-day waves in a numerical model of the Pacific. J. Phys. Oceanogr., 10,1168-1186, doi:10.1175/1520-0485(1980)010<1168:GAPODW>2.0.CO;2.

Dong, C. M., Y. Liu, R. Lumpkin, M. Lankhorst, D. Chen, J. C. McWilliams, and Y. P. Guan, 2011: A scheme to identify loops from trajectories of oceanic surface drifters: An application in the Kuroshio Extension region. J. Atmos. Oceanic Technol., 28, 1167-1176, doi:10.1175/JTECH-D-10-05028.1.

, J. C. McWilliams, Y. Liu, and D. Chen, 2014: Global heat and salt transports by eddy movement. Nat. Commun., 5, 3294, doi:10.1038/ncomms4294.

Donohue, K. A., and M. Wimbush, 1998: Model results of flow instabilities in the tropical Pacific Ocean. J. Geophys. Res., 103, 21 401-21 412, doi:10.1029/98JC01912.

Flament, P. J., S. C. Kennan, R. A. Knox, P. P. Niiler, and R. L. Bernstein, 1996: The three-dimensional structure of an upper ocean vortex in the tropical Pacific Ocean. Nature, 383, 610613, doi:10.1038/383610a0.

, R. Lumpkin, J. Tournadre, and L. Armi, 2001: Vortex pairing in an unstable anticyclonic shear flow: Discrete subharmonics of one pendulum day. J. Fluid Mech., 440, 401-409, doi:10.1017/S0022112001004955. 
Hansen, D. V., and C. A. Paul, 1984: Genesis and effects of long waves in the equatorial Pacific. J. Geophys. Res., 89, $10431-$ 10 440, doi:10.1029/JC089iC06p10431.

—, and G. A. Maul, 1991: Anticyclonic current rings in the eastern tropical Pacific Ocean. J. Geophys. Res., 96, 69656979, doi:10.1029/91JC00096.

—_, and P. M. Poulain, 1996: Quality control and interpolations of WOCE-TOGA drifter data. J. Atmos. Oceanic Technol., 13, 900-909, doi:10.1175/1520-0426(1996)013<0900: QCAIOW $>2.0 . \mathrm{CO} ; 2$.

_ C. A. Paul, and R. Legeckis, 1980: Comparison of satellite and direct current observations of long waves in the eastern tropical Pacific during FGGE. Eos, Trans. Amer. Geophys. Union, 61, 993.

Holmes, R. M., and L. N. Thomas, 2015: The modulation of equatorial turbulence by tropical instability waves in a regional ocean model. J. Phys. Oceanogr., 45, 1155-1173, doi:10.1175/JPO-D-14-0209.1.

,$- \ldots$, L. Thompson, and D. Darr, 2014: Potential vorticity dynamics of tropical instability vortices. J. Phys. Oceanogr., 44, 995-1011, doi:10.1175/JPO-D-13-0157.1.

Inoue, R., R. C. Lien, and J. N. Moum, 2012: Modulation of equatorial turbulence by a tropical instability wave. J. Geophys. Res., 117, C10009, doi:10.1029/2011JC007767.

Jochum, M., M. F. Cronin, W. S. Kessler, and D. Shea, 2007: Observed horizontal temperature advection by tropical instability waves. Geophys. Res. Lett., 34, L09604, doi:10.1029/ 2007GL029416.

Johnson, E. S., F. Bonjean, G. S. E. Lagerloef, J. T. Gunn, and G. T. Mitchum, 2007: Validation and error analysis of OSCAR sea surface currents. J. Atmos. Oceanic Technol., 24, 688-701, doi:10.1175/JTECH1971.1.

Johnson, G. C., B. M. Sloyan, W. S. Kessler, and K. E. McTaggart, 2002: Direct measurements of upper ocean currents and water properties across the tropical Pacific during the 1990s. Prog. Oceanogr., 52, 31-61, doi:10.1016/S0079-6611(02)00021-6.

Kashino, Y., A. Atmadipoera, Y. Kuroda, and Lukijanto, 2013: Observed features of the Halmahera and Mindanao eddies. J. Geophys. Res. Oceans, 118, 6543-6560, doi:10.1002/ 2013 JC009207.

Kennan, S. C., and P. J. Flament, 2000: Observations of a tropical instability vortex. J. Phys. Oceanogr., 30, 2277-2301, doi:10.1175/ 1520-0485(2000)030<2277:OOATIV >2.0.CO;2.

Lankhorst, M., 2006: A self-contained identification scheme for eddies in drifter and float trajectories. J. Atmos. Oceanic Technol., 23, 1583-1592, doi:10.1175/JTECH1931.1.

Legeckis, R., 1977: Long waves in eastern equatorial Pacific Ocean: A view from a geostationary satellite. Science, 197, 1179-1181, doi:10.1126/science.197.4309.1179.

__ W. Pichel, and G. Nesterczuk, 1983: Equatorial long waves in geostationary satellite observations and in a multichannel sea surface temperature analysis. Bull. Amer. Meteor. Soc., 64, 133-139, doi:10.1175/1520-0477(1983)064<0133: ELWIGS $>2.0 . \mathrm{CO} ; 2$.

—_ C. W. Brown, F. Bonjean, and E. S. Johnson, 2004: The influence of tropical instability waves on phytoplankton blooms in the wake of the Marquesas Islands during 1998 and on the currents observed during the drift of the Kon-Tiki in 1947. Geophys. Res. Lett., 31, L23307, doi:10.1029/2004GL021637.

Li, J., R. Zhang, and B. Jin, 2011: Eddy characteristics in the northern South China Sea as inferred from Lagrangian drifter data. Ocean Sci., 7, 661-669, doi:10.5194/os-7-661-2011.
Liang, J.-H., J. C. McWilliams, J. Kurian, F. Colas, P. Wang, and Y. Uchiyama, 2012: Mesoscale variability in the northeastern tropical Pacific: Forcing mechanisms and eddy properties. J. Geophys. Res., 117, C07003, doi:10.1029/2012JC008008.

Lien, R.-C., E. A. D'Asaro, and C. E. Menkes, 2008: Modulation of equatorial turbulence by tropical instability waves. Geophys. Res. Lett., 35, L24607, doi:10.1029/2008GL035860.

Lumpkin, R., 2016: Global characteristics of coherent vortices from surface drifter trajectories. J. Geophys. Res. Oceans, 121, 1306-1321, doi:10.1002/2015JC011435.

_ , and M. Pazos, 2007: Measuring surface currents with surface velocity program drifters: The instrument, its data, and some recent results. Lagrangian Analysis and Prediction of Coastal and Ocean Dynamics, A. Griffa et al., Eds., Cambridge University Press, 39-67.

_ from drifters: Mean, variance, El Niño-Southern Oscillation response, and seasonal cycle. J. Geophys. Res. Oceans, 118, 2992-3006, doi:10.1002/jgrc.20210.

Luther, D. S., and E. S. Johnson, 1990: Eddy energetics in the upper equatorial Pacific during the Hawaii-to-Tahiti Shuttle Experiment. J. Phys. Oceanogr., 20, 913-944, doi:10.1175/ 1520-0485(1990)020<0913:EEITUE >2.0.CO;2.

Lyman, J. M., D. B. Chelton, R. A. deSzoeke, and R. M. Samelson, 2005: Tropical instability waves as a resonance between equatorial Rossby waves. J. Phys. Oceanogr., 35, 232-254, doi:10.1175/JPO-2668.1.

- G. C. Johnson, and W. S. Kessler, 2007: Distinct 17- and 33-day tropical instability waves in subsurface observations. J. Phys. Oceanogr., 37, 855-872, doi:10.1175/JPO3023.1.

Malardé, J. P., P. Demey, C. Perigaud, and J. F. Minster, 1987: Observation of long equatorial waves in the Pacific Ocean by Seasat altimetry. J. Phys. Oceanogr., 17, 2273-2279, doi:10.1175/ 1520-0485(1987)017<2273:OOLEWI>2.0.CO;2.

Masina, S., S. G. H. Philander, and A. B. G. Bush, 1999: An analysis of tropical instability waves in a numerical model of the Pacific Ocean: 2. Generation and energetics of the waves. J. Geophys. Res., 104, 29 637-29 661, doi:10.1029/1999JC900226.

Masumoto, Y., and Coauthors, 2004: A fifty-year eddy-resolving simulation of the World Ocean-Preliminary outcomes of OFES (OGCM for the Earth Simulator). J. Earth Simul., 1, $31-52$.

Menkes, C. E. R., J. G. Vialard, S. C. Kennan, J. P. Boulanger, and G. V. Madec, 2006: A modeling study of the impact of tropical instability waves on the heat budget of the eastern equatorial Pacific. J. Phys. Oceanogr., 36, 847-865, doi:10.1175/ JPO2904.1.

Morrow, R., F. Birol, D. Griffin, and J. Sudre, 2004: Divergent pathways of cyclonic and anti-cyclonic ocean eddies. Geophys. Res. Lett., 31, L24311, doi:10.1029/2004GL020974.

Moum, J. N., R. C. Lien, A. Perlin, J. D. Nash, M. C. Gregg, and P. J. Wiles, 2009: Sea surface cooling at the equator by subsurface mixing in tropical instability waves. Nat. Geosci., 2 , 761-765, doi:10.1038/ngeo657.

_ A. Perlin, J. D. Nash, and M. J. McPhaden, 2013: Seasonal sea surface cooling in the equatorial Pacific cold tongue controlled by ocean mixing. Nature, 500, 64-67, doi:10.1038/nature12363.

Palacios, D. M., and S. J. Bograd, 2005: A census of Tehuantepec and Papagayo eddies in the northeastern tropical Pacific. Geophys. Res. Lett., 32, L23606, doi:10.1029/2005GL024324.

Philander, S. G. H., 1978: Instabilities of zonal equatorial currents. 2. J. Geophys. Res., 83, 3679-3682, doi:10.1029/ JC083iC07p03679. 
Proehl, J. A., 1996: Linear stability of equatorial zonal flows. J. Phys. Oceanogr., 26, 601-621, doi:10.1175/1520-0485(1996)026<0601: $\mathrm{LSOEZF}>2.0 . \mathrm{CO} ; 2$.

Qiao, L., and R. H. Weisberg, 1995: Tropical instability wave kinematics: Observations from the tropical instability wave experiment. J. Geophys. Res., 100, 8677-8693, doi:10.1029/ 95JC00305.

_, and - 1997: The zonal momentum balance of the Equatorial Undercurrent in the central Pacific. J. Phys. Oceanogr., 27, 1094-1119, doi:10.1175/1520-0485(1997)027<1094: TZMBOT $>2.0 . \mathrm{CO} ; 2$.

Sasaki, H., M. Nonaka, Y. Masumoto, Y. Sasai, H. Uehara, and H. Sakuma, 2008: An eddy-resolving hindcast simulation of the quasiglobal ocean from 1950 to 2003 on the Earth Simulator. High Resolution Numerical Modelling of the Atmosphere and Ocean, K. Hamilton and W. Ohfuchi, Eds., Springer, 157-185.

Shoosmith, D., P. L. Richardson, A. S. Bower, and H. T. Rossby, 2005: Discrete eddies in the northern North Atlantic as observed by looping RAFOS floats. Deep-Sea Res. II, 52, 627650, doi:10.1016/j.dsr2.2004.12.011.

Talley, L. D., G. L. Pickard, W. J. Emery, and J. H. Swift, 2011: Descriptive Physical Oceanography: An Introduction. 6th ed. Elsevier, $560 \mathrm{pp}$.

Trenberth, K. E., J. M. Caron, D. P. Stepaniak, and S. Worley, 2002: Evolution of El Niño-Southern Oscillation and global atmospheric surface temperatures. J. Geophys. Res., 107, 4065, doi:10.1029/2000JD000298.
Ubelmann, C., and L. L. Fu, 2011: Vorticity structures in the tropical Pacific from a numerical simulation. J. Phys. Oceanogr., 41, 1455-1464, doi:10.1175/2011JPO4507.1.

Vialard, J., C. Menkes, J. P. Boulanger, P. Delecluse, E. Guilyardi, M. J. McPhaden, and G. Madec, 2001: A model study of oceanic mechanisms affecting equatorial Pacific sea surface temperature during the 1997-98 El Niño. J. Phys. Oceanogr., 31, 1649-1675, doi:10.1175/1520-0485(2001)031<1649: AMSOOM $>2.0 . \mathrm{CO} ; 2$.

Weidman, P. D., D. L. Mickler, B. Dayyani, and G. H. Born, 1999: Analysis of Legeckis eddies in the near-equatorial Pacific. J. Geophys. Res., 104, 7865-7887, doi:10.1029/1998JC900057.

Willett, C. S., R. R. Leben, and M. F. Lavin, 2006: Eddies and tropical instability waves in the eastern tropical Pacific: A review. Prog. Oceanogr., 69, 218-238, doi:10.1016/j.pocean.2006.03.010.

Wyrtki, K., 1974: Sea-level and seasonal fluctuations of equatorial currents in the western Pacific Ocean. J. Phys. Oceanogr., 4, 91103, doi:10.1175/1520-0485(1974)004<0091:SLATSF > 2.0.CO;2.

Yu, J. Y., and W. T. Liu, 2003: A linear relationship between ENSO intensity and tropical instability wave activity in the eastern Pacific Ocean. Geophys. Res. Lett., 30, 1735, doi:10.1029/ 2003GL017176.

Zhang, Z. G., W. Wang, and B. Qiu, 2014: Oceanic mass transport by mesoscale eddies. Science, 345, 322-324, doi:10.1126/ science. 1252418.

Zheng, S., Y. Du, J. Li, and X. Cheng, 2015: Eddy characteristics in the south Indian Ocean as inferred from surface drifters. Ocean Sci., 11, 361-371, doi:10.5194/os-11-361-2015. 